\title{
Elastic Foundation Beam Analysis on Rigid Pavement and Piles
}

\author{
Syamsul Arifin ${ }^{1,}$, Anwar Dolu ${ }^{1}$, and Agus Rivani ${ }^{1}$ \\ ${ }^{1}$ Department of Civil Engineering, Tadulako University, Palu, Indonesia
}

\begin{abstract}
In this study, the rigid pavement structure and pile foundation were modeled as the foundation of the Winkler elastic beam. for pavement with distribution loads and traffic loads, and variations in support. While for pile foundations with lateral loads. Solution of analytical differential equations with computer applications (CAS) Maple. The aim of this research are : (a). To know whether completion of algebraic computer application can be obtained by analytically method or numerically method, (b). To check whether analytical model is possible to be applied to various loads at any point in the beam or not, (c). Where of the strength or the displacement boundary to be located in the beam during load application, (d). To verify an approach possibility implementation of a simple computer algebra system, (e). To know whether achieved solutions which possible to solve ordinary differential equation (ODE) can be implemented in any mathematical system.
\end{abstract}

\section{Introduction}

The concept of beams on elastic foundations was first developed by E. Winkler in 1867. Since then it has been applied by Terzaghi and many others to geotechnical problems in which ground or subgrade is supporting media. Analysis of bending of beams on an elastic foundation is developed on the assumption that the reaction forces of the foundation are proportional at every point to the deflection of the beam at that point. This assumption was introduced by E. Winkler, formed the basis of H. Zimmermann's classic work on railroad track, published in 1888 [1, 2, 3]. Application example of the concept of elastic foundation consists of various structures including foundation beams and footings, piles, retaining walls, piles and many others $[2,3,4,5,6]$

\section{Differential Equations of Elastic Foundation}

By reviewing the foundation beams, along the span is supported by the ground and receives vertical loads. The reaction that occurs according to the basic assumption, the intensity of $p$ at each point is proportional to the deflection of the beam (y) at that point

$$
p=k y=b k_{o} y
$$

\footnotetext{
*Corresponding author: syam arfn@yahoo.com
} 
For $b$ is the width of the foundation, and ko is the modulus of foundation. By reviewing the small element of the beam along $d x$ with the load $q$. Considering the equilibrium of the element in Fig. 1b, we find that the summation of the vertical forces gives

$$
Q-(Q+d Q)+k y d x-q d x=0
$$

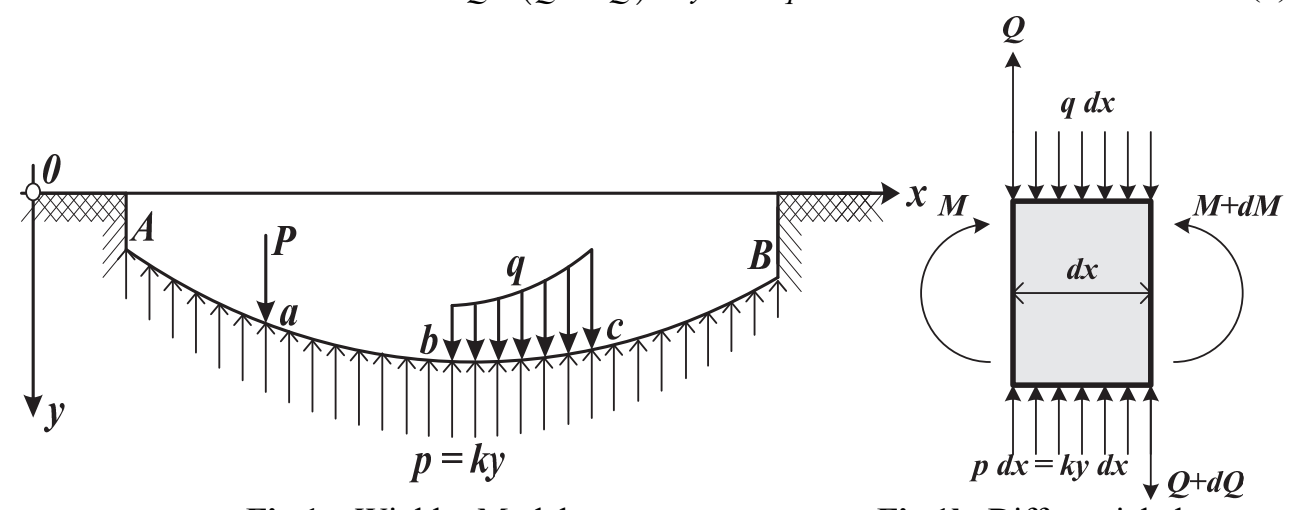

Fig.1a. Winkler Model

Fig.1b. Differential element

Fig. 1. Beam on Elastic foundation $[1,2,3]$

In simple form

$$
\frac{d Q}{d x}=\frac{d^{2} M}{d x^{2}}=k y-q
$$

Using the relationship $Q=d M / d x$, it can be written

$$
E I \frac{d^{4} y}{d x^{4}}=-\frac{d^{2} M}{d x^{2}}
$$

According to equation $(3,4)$, then obtained

$$
E I \frac{d^{4} y}{d x^{4}}+k y=q
$$

In simple form equations (5)

$$
\frac{d^{4} y}{d x^{4}}+4 \alpha^{4} y=\frac{q(x)}{E I} \quad ; \quad \alpha=\sqrt[4]{\frac{k}{4 E I}}
$$

Solution of differential equations from Equation (6)

$$
y(x)=y_{h}(x)+y_{p}(x)
$$

Where $y_{h}(x)$ is the solution of homogeneous differential equation $y^{I V}+4 \alpha^{4} y=0$, and $y_{p}(x)$ is a particular integral corresponding to $\mathrm{q}(\mathrm{x})$. General form of solving differential equations (6) and equations (7)

$$
\begin{aligned}
y(x) & =C_{1} e^{\alpha x} \cos (\alpha x)+C_{2} e^{\alpha x} \sin (\alpha x)+C_{3} e^{-\alpha x} \cos (\alpha x) \\
& +C_{4} e^{-\alpha x} \sin (\alpha x)+\frac{q}{4 E I \alpha^{4}}
\end{aligned}
$$

The integration constants $\mathrm{C}_{1}, \mathrm{C}_{2}, \mathrm{C}_{3}, \mathrm{C}_{4}$, appearing in equation are determined the following boundary conditions $(\mathrm{BCs})[4,6,7,8]$ 


$$
\begin{aligned}
& \frac{d^{2} y}{d x^{2}}(0)=0 \quad \text { and } \quad \frac{d^{3} y}{d x^{3}}(0)=0 \quad \text { for free - free end } \\
& \frac{d^{2} y}{d x^{2}}(L)=0 \quad \text { and } \quad \frac{d^{3} y}{d x^{3}}(L)=0 \\
& y(0)=0 \quad \text { and } \quad \frac{d^{2} y}{d x^{2}}(0)=0 \quad \text { for pinned - pinned end } \\
& y(L)=0 \quad \text { and } \quad \frac{d^{2} y}{d x^{2}}(L)=0 \\
& y(0)=0 \quad \text { and } \quad \frac{d y}{d x}(0)=0 \quad \text { for clamped - clamped en } \\
& y(L)=0 \quad \text { and } \quad \frac{d y}{d x}(L)=0 \quad
\end{aligned}
$$

\section{Pile With Lateral Loads}

The structural analysis of vertical piles with lateral loads gives almost the same boundary value problem (BVP) as a beam on an elastic foundation. The differences are in the loading which is concentrated at the pile's top and in the elastic foundation model. The pile foundation model includes variable spring stiffness while the beam model has constant stiffness of the bed's springs $[3,4,5,9,10,11]$.

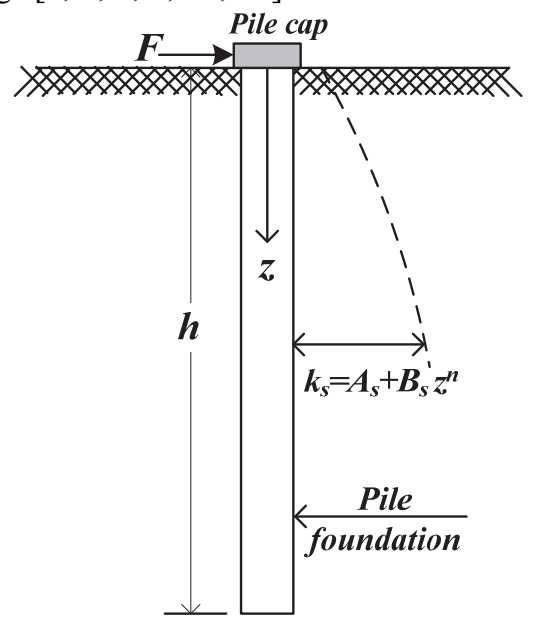

Fig. 2. Pile foundations with lateral load

In accordance with Equation (6), with load distributed (q) along the beam $=0$, and the modulus of the foundation is a function of depth $\mathrm{k}=\mathrm{f}(\mathrm{z})$, the following equation is obtained

$$
E I \frac{d^{4} x(z)}{d z^{4}}+k(z) b x(z)=0
$$

Values of ks from Bowles [5]

$$
k_{s}(z)=A_{s}+B_{s} Z^{n}
$$

The pile top has mixed boundary conditions and the bottom has force boundary conditions 


$$
\begin{aligned}
& \frac{d x}{d z}(0)=0 \quad \text { and } \quad-E I \frac{d^{3} x}{d z^{3}}(0)=-F \\
& -E I \frac{d^{2} x}{d z^{2}}(H)=0 \quad \text { and } \quad-E I \frac{d^{3} x}{d z^{3}}(H)=0
\end{aligned}
$$

\section{Numerical Example}

\subsection{Beam / Plates Rigid Pavement}

Consider a beam on elastic foundation with free ends. The geometrical dimensions, mechanical properties and loadings are shown in Fig. 3. The modulus of elasticity of concrete is $\mathrm{E}_{\mathrm{c}}=23500 \mathrm{MPa}$ and the modulus of the foundation is $k_{0}=50.000 \mathrm{kN} / \mathrm{m}^{3}$. Width of rigid pavement bo $=2.0 \mathrm{~m}$.

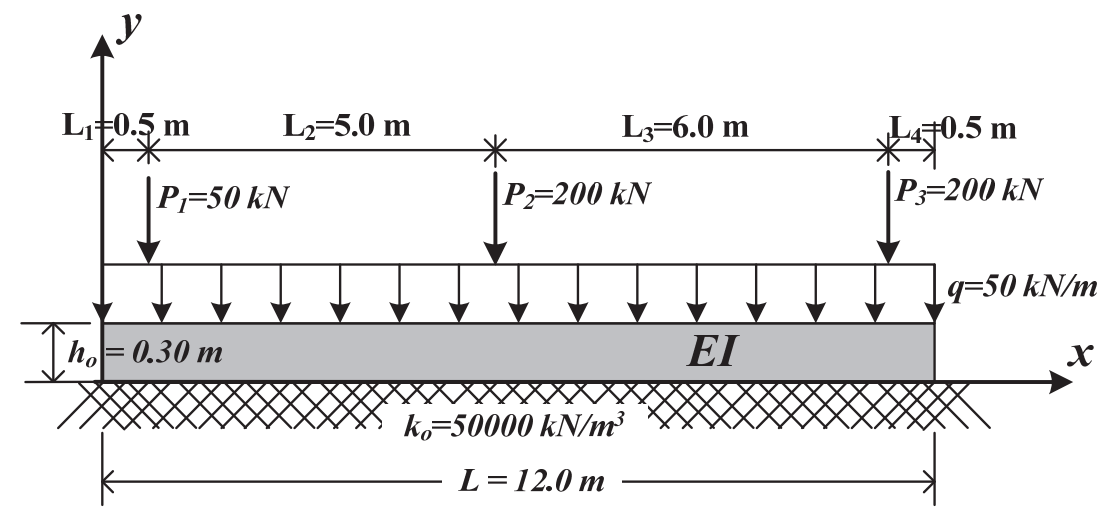

Fig. 3. Rigid Pavement with distributed load and traffic load

In accordance with the equation $(6,8,10,11,12)$, with the substitution of parameters according to Figure 3, it is obtained

$$
105750 \frac{d^{4} y}{d x^{4}}+100000 y=q(x)
$$

The loads $\mathrm{q}(\mathrm{x})$ can be presented by singularity functions as [4]

$$
q(x)=q+P_{1} \delta(x-a)+P_{2} \delta(x-b)+P_{3} \delta(x-c)
$$

where $a$ is the distance from the force $P_{1}$ to the left end of the beam; $b$ is the distance from the beam's left end to the beginning of the force $P_{2} ; c$ is the distance from the beam's left end to the force $P_{3}$. For $\delta(x-a)$ notation is the Dirac delta function.

Equation $(15,16)$ is solved numerically with the CAS Maple application, with code :

Sol:=evalf(dsolve( $\{$ de,ibc $\}, y(x)))$ :

The calculation results can be seen in Table 1 and Figure 4, 5, 6 
Table 1. Analysis Results of Rigid Pavement Structure

\begin{tabular}{l|c|c|c}
\hline \multirow{2}{*}{ Parameter } & \multicolumn{3}{|c}{ Support type } \\
\cline { 2 - 4 } & $\begin{array}{l}\text { Clamped }- \\
\text { clamped }\end{array}$ & $\begin{array}{l}\text { Pinned }- \\
\text { pinned }\end{array}$ & $\begin{array}{l}\text { Free - } \\
\text { free }\end{array}$ \\
\hline Moment $(\mathrm{x}=0)$ & 64.722 & 0 & 0 \\
\hline Moment $(\mathrm{x}=5.5 \mathrm{~m})$ & -71.126 & -69.825 & -73.674 \\
\hline Moment $(\mathrm{x}=12 \mathrm{~m})$ & 117.492 & 0 & 0 \\
\hline Shear $(\mathrm{x}=0)$ & -110.842 & -65.727 & 0 \\
\hline Shear $(\mathrm{x}=5.50 \mathrm{~m})$ & -98.892 & -99.240 & -100.880 \\
\hline Shear $(\mathrm{x}=12.0 \mathrm{~m})$ & 250.05 & 168.131 & 0 \\
\hline
\end{tabular}

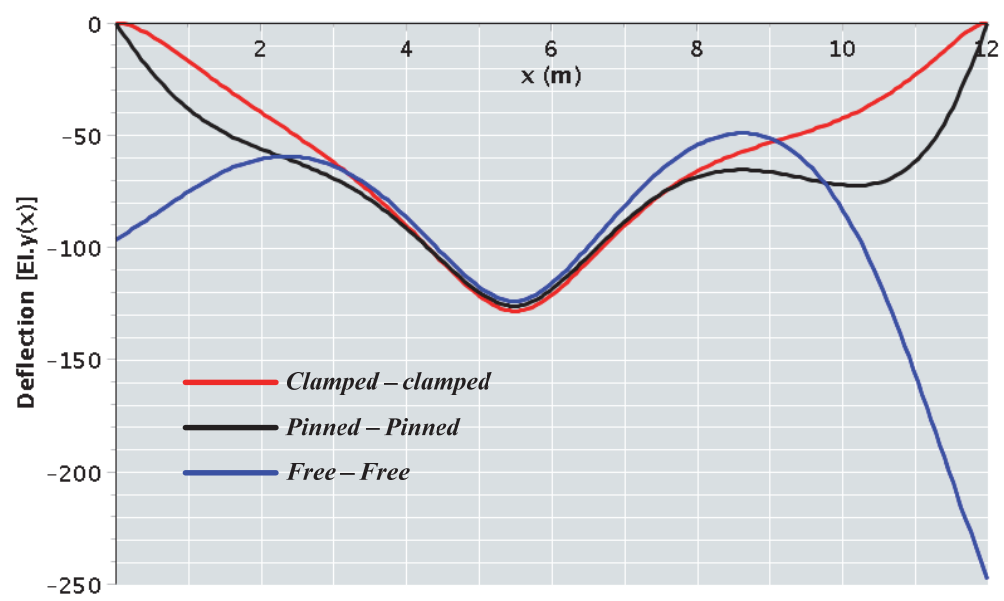

Fig. 4. Displacements of Rigid Pavement with various type of support

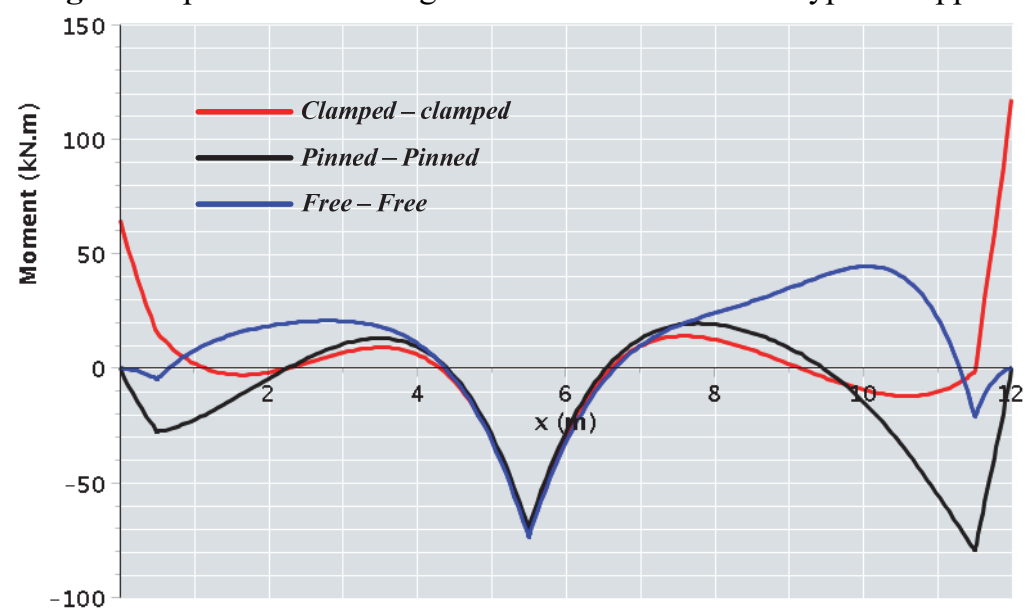

Fig. 5. Bending Moments with various type of support. 


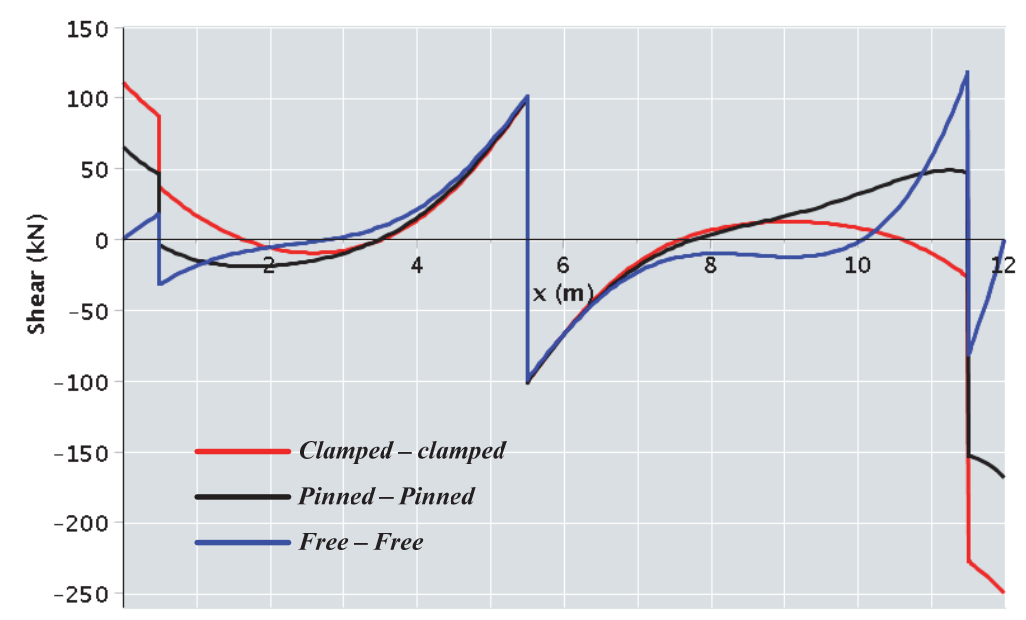

Fig. 6. Shear forces with various type of support.

\subsection{Pile Foundations with Lateral Load}

From Bowles [5], the pile is a steel section HP $360 \times 174, b=378 \mathrm{~mm}$, Moment Inertia Ix = $0.5080 \times 10^{-3} \mathrm{~m}^{4}$, Modulus of Elasticity $\mathrm{E}=200 \mathrm{Gpa}$, and $19 \mathrm{~m}$ long. Bending stiffness of $E I=101600 \mathrm{kNm}^{2}$. The pile is loaded with a lateral force $F=50.78 \mathrm{kN}$ at the top and it is assumed that the top end is fixed in the pile cap. The soil stiffness variation [5]

$$
k=200+50 \sqrt{z}
$$

In accordance with equation $(12,13)$ then obtained

$$
101600 \frac{d^{4} x(z)}{d z^{4}}+(75.60+18.90 \sqrt{z}) x(z)=0
$$

Boundary conditions (BCs) according to equation (14),

$$
\begin{aligned}
& \frac{d x}{d z}(0)=0 \quad \text { and } \quad-101600 \frac{d^{3} x}{d z^{3}}(0)=-50.78 \\
& -101600 \frac{d^{2} x}{d z^{2}}(19)=0 \quad \text { and } \quad-101600 \frac{d^{3} x}{d z^{3}}(19)=0
\end{aligned}
$$

Equation $(18,19)$ is solved numerically with the CAS Maple application, with code :

Sol: $=$ dsolve( $\{$ de,, $\mathrm{bc}\},\{x(\mathrm{z})\}$, numeric);

Based on the results obtained analytically by solving differential equations, and comparing the results of analysis from Bowles [5] using the finite element method (FEM), for maximum deflection there is a difference of $0.28 \%$, maximum moment of $-0.16 \%$ and soil pressure $(\mathrm{z}$ $=0$ ) difference of $0.30 \%$. 
Table 2. Analysis Results of Pile with Lateral Load

\begin{tabular}{r|c|r|c|r|c|c}
\hline \multirow{2}{*}{$\begin{array}{c}\text { Depth } \\
(\mathrm{m})\end{array}$} & \multicolumn{2}{|c|}{ Displacement $(\mathrm{m})$} & \multicolumn{2}{c|}{ Moment $(\mathrm{kN})$} & \multicolumn{2}{c}{ Reaction $(\mathrm{kN})$} \\
\cline { 2 - 7 } & Present & $\begin{array}{c}\text { Bowles } \\
{[5]}\end{array}$ & Present & $\begin{array}{c}\text { Bowles } \\
{[5]}\end{array}$ & Present & $\begin{array}{c}\text { Bowles } \\
{[5]}\end{array}$ \\
\hline \hline 0 & 0,06223 & 0,06206 & 208,154 & 208,483 & 12,45 & 12,41 \\
\hline 1.0 & 0,06129 & 0,06112 & 160,033 & 159,988 & 15,32 & 15,28 \\
\hline 2.0 & 0,05877 & 0,05859 & 117,659 & 117,161 & 15,91 & 15,86 \\
\hline 3.0 & 0,05508 & 0,05489 & 81,277 & 80,320 & 15,79 & 15,73 \\
\hline 4.5 & 0,04814 & 0,04794 & 37,799 & 36,281 & 14,73 & 14,67 \\
\hline 6.0 & 0,04034 & 0,04014 & 6,805 & 4,698 & 13,01 & 12,94 \\
\hline 8.0 & 0,02975 & 0,02959 & $-17,654$ & $-20,218$ & 10,16 & 10,1 \\
\hline 10.0 & 0,01981 & 0,01973 & $-26,780$ & $-29,876$ & 7,09 & 7,07 \\
\hline 13.0 & 0,00680 & 0,00697 & $-21,784$ & $-24,209$ & 2,59 & 2,65 \\
\hline 16.0 & $-0,00434$ & $-0,00378$ & $-7,927$ & $-9,535$ & 1,73 & 1,51 \\
\hline 19.0 & $-0,01473$ & $-0,01361$ & 0,000 & 0,000 & 6,16 & 5,69 \\
\hline
\end{tabular}
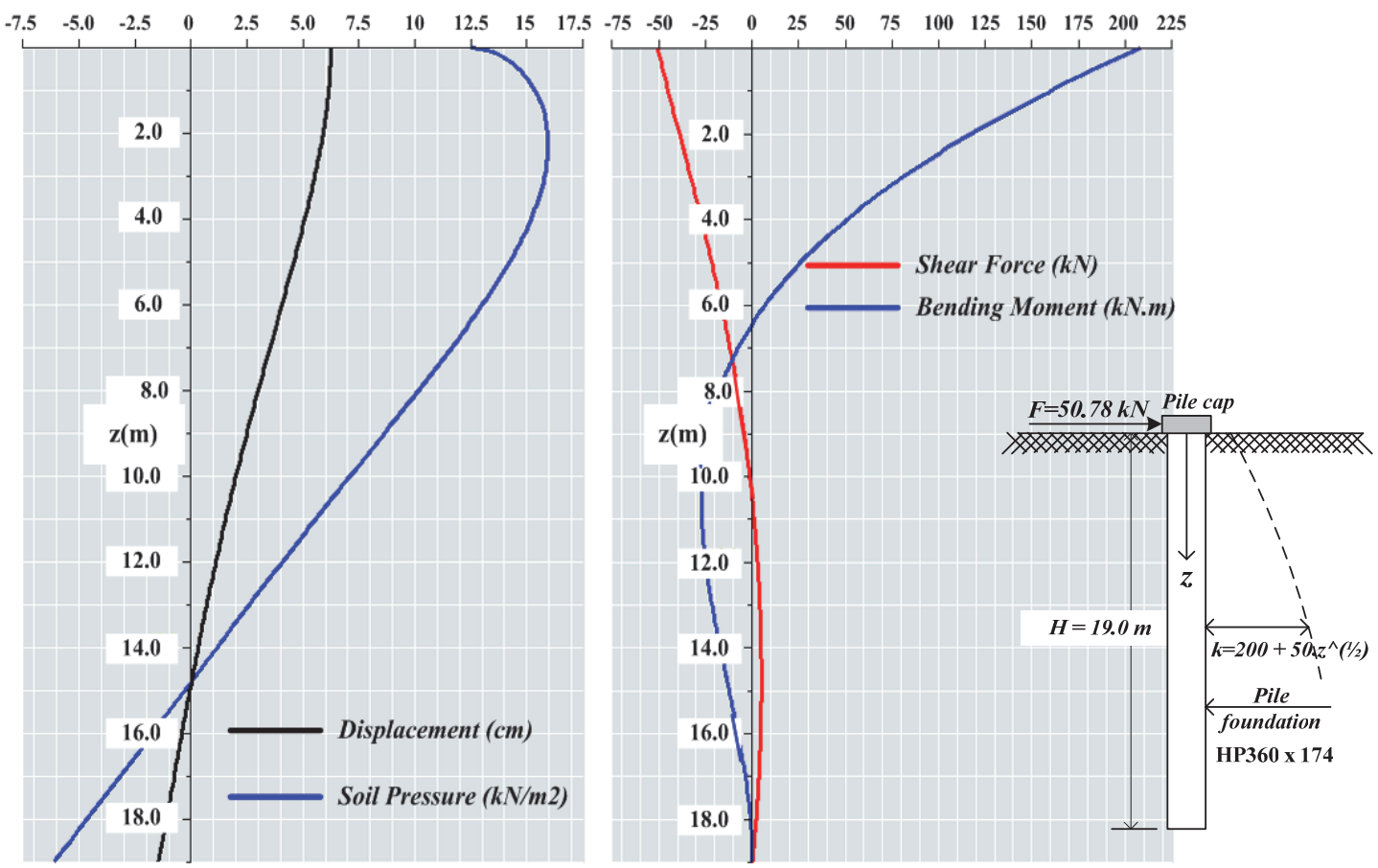

Fig. 7. Displacement, Soil Pressure, Shear Forces and Bending Moment in Pile foundations 


\section{Conclusion}

Analysis of elastic foundation with the Winkler model can be used in general for the solution of rigid pavement structures, and soil-pile interaction approaches.

- Completion of algebraic computer applications can be obtained analytically or numerically.

- Analytical model can be applied to various loads at any point in the beam,

- Application of conditions to the strength or displacement boundary at the end of the beam.

- Implementation of an approach to a simple computer algebra system

- Solutions presented can be implemented in any mathematical system that can solve Ordinary Differential Equations (ODE)

- The analytical solutions obtained can be used to analyze the effect of different parameters on structural behavior.

\section{References}

1. M. Hetenyi, Beams on Elastic Foundation, Ann Arbor, The University Michigan Press, (1946)

2. G. Jones Analysis of Beams on Elastic Foundations: Using Finite Difference Theory, Thomas Telford (1997)

3. E.S. Melerski, Design Analysis of Beams, Circular Plates and Cylindrical Tanks on Elastic Foundation, Second Edition., (Taylor \& Francis Group, London, UK, 2006)

4. D. Dinev, Analytical solution of beam on elastic Foundation by singularity functions, Engineering Mechanics, vol. 19, , no. 6, p. 381-392, (2012)

5. JE. Bowles. Foundation Analysis and Design, Fifth Edition, McGraw-Hill (1995)

6. BJS. Breeveld, Modelling the Interaction between Structure and Soil for Shallow Foundations, A Computational Modelling Approach, Master of Science Thesis, Delft University of Technology (TU Delft)

7. K. Tiwari, R. Kuppa, Overview of Methods of Analysis of Beams on Elastic Foundation Journal of Mechanical and Civil Engineering (IOSR-JMCE), Volume 11, Issue 5 Ver. VI, PP 22-29, (Sep-Oct. 2014)

8. S. Parvanova, Beams on elastic foundation, Lecture notes: Structural Analysis II, University of Architecture, Civil Engineering and Geodesy - Sofia, (2011)

9. Kalavathi GN, Muralidhar. Behavior of Piles under Lateral Loading Soil Structure Interaction, Journal of Mechanical and Civil Engineering (IOSR-JMCE) Volume 12, Issue 2 Ver. V PP 68-74, (Mar - Apr. 2015)

10. Y. Khodair1 A Abdel-Mohti, Numerical Analysis of Pile-Soil Interaction under Axial and Lateral Loads. International Journal of Concrete Structures and Materials, Vol.8, No.3, pp.239-249, (September 2014)

11. P.E. Kavitha, K.S. Beena, K.P. Narayanan. A review on soil-structure interaction analysis of laterally loaded piles. Innov. Infrastruct. Solut. (2016) 